\title{
Phi-feature inflection and agreement: An introduction
}

\author{
Marcel den Dikken
}

Published online: 20 October 2011

(C) Springer Science+Business Media B.V. 2011

\begin{abstract}
The linguistic literature abounds with discussions of phi-feature inflection. The formalist tradition has, in a variety of ways, approached this phenomenon predominantly in terms of an agreement relationship between two terms of a syntactic structure-for instance, the subject and the finite verb (typically showing agreement for person and number), or the object and a past participle (which, e.g. in the Romance languages, may agree for number and gender, but not for person). But not all these agreement relationships affect all phi-features equally, which raises the question of whether there is to be a unified approach to phi-features in general. And two terms that can entertain an agreement relationship for certain phi-features do not seem to engage in such agreement every time they might be expected to so do. On the surface, plural subjects can co-occur with singularly inflected finite verbs, and vice versa; and sometimes a subpart of the subject seems to control the selection of the inflection on the finite verb, in so-called 'attraction' cases. These kinds of phenomena give rise to an in-depth exploration of the nature and reality of agreement relationships, including the possibility of an analysis treating phi-featural properties as autonomous vis-à-vis one another, assigned to each term separately, not under agreement. This special issue brings together a collection of papers and commentaries reflecting on these matters in various ways. In this introduction, I set the stage for the discussion to follow.
\end{abstract}

Keywords Agreement · Phi-features · Person · Number · Notional agreement · Attraction

\section{Introduction}

The properties of phi-feature inflection (where 'phi' is a cover for at least person, number and gender, and possibly also animacy and definiteness or specificity) are of-

M. den Dikken $(\bowtie)$

Linguistics Program, CUNY Graduate Center, New York, NY, USA

e-mail: MDen-Dikken@gc.cuny.edu 
ten brought forward as a window on the structural configuration or configurations in which the relationship of agreement can take effect-where 'agreement' is construed as a relationship between two terms of a syntactic structure, for instance, the subject and the finite verb. The facts of phi-feature inflection in the world's languages are highly complex, with some of the biggest puzzles being posed by what are at first blush unexpected breakdowns of, restrictions on, or cases of 'infectious' multiple exponence of phi-feature inflection. Since the facts are so complicated, it is hardly surprising that they have given rise to a variety of perspectives on how phi-feature relationships should be structurally represented. Many researchers have approached them strictly from the point of view of morphosyntactic theory, without semantics playing a role at all. Others have made a distinction between grammatical/formal and notional agreement relations, with some of these scholars highlighting the importance of the human sentence-processing mechanism, focusing particularly on phi-feature inflections that seem 'aberrant' from a strictly syntactic point of view. And still others have denied outright that any so-called phi-feature agreement is a semantically meaningless, purely formal relationship between two terms in a syntactic structure, and have attributed precise semantic contributions to the choice of inflectional forms.

There are many studies in the linguistic literature that concentrate on one of these positions wholesale. But it is always worth one's while to confront such studies with each other to see where they stand up to scrutiny and where they give way. The truth might very well lie somewhere in between the extremes, so it is important to carefully investigate the division of labour between the various perspectives. The purpose of this special issue is to explore the limits of and the possible interactions between the various perspectives on phi-feature inflection, by bringing together a maximally colourful palette of such perspectives. In putting the picture together, we will be assisted here by ten specialists in their fields. This special issue is a collection of five full-length articles and four commentaries. In these introductory remarks, I will provide a general background to these nine contributions by focusing on the central themes that they address, placing these themes in a broader perspective, and raising general as well as specific questions that future research on phi-features would do well to think about at more length.

\section{Person versus number}

The first two contributions to this special issue, by Mark Baker and Andrew Nevins, pay particular attention to the fact that person and number are two very different entities when it comes to so-called agreement phenomena. Baker talks about cases in which agreement is for number and gender but not for person; Nevins capitalises on the absence of the equivalent to Person Case Constraint (PCC) effects in the realm of number, and on the 'omnivory' that number agreement can give rise to. The picture emerging from these two studies, that there is a profound difference between person and number, is relativised to some degree in the two commentaries, by Omer Preminger and Susana Bejar.

Baker's central point, which he makes on the basis of a detailed investigation of facts from a variety of languages, can be illustrated very simply with reference to the 
phi-feature matching relationships between predicates and their subjects: when the predicate head is a finite verb, that finite verb (in languages that have the morphological wherewithal to bring this out) can show the same person and number properties as its subject, and sometimes (as in Russian and Hebrew) the two may also agree for gender; but when the predicate head is an adjective, as in the bracketed portion of They consider [us smart], the adjective can only show agreement with its subject for number and gender, never for person, even in languages in which a form of the adjective showing inflection for all three phi-features simultaneously could be straightforwardly constructed in principle. Thus, Spanish list-, the root for 'smart', can combine with a gender morpheme (e.g., feminine $-a$ ) and then a number morpheme (plural $-s$ ), forming list-a-s 'smart-f-pl'; but although list-a-mos could logically be composed out of list-, feminine $-a$, and first person plural -mos, the form listamos actually occurs only as the first person plural present indicative form of the verb listar 'to list', not as the adjective in the Spanish rendition of They consider [us smart], which can only be inflected for gender and number.

For Baker, this reveals a fundamental difference between person on the one hand, and number and gender on the other, in the way in which agreement relationships involving these phi-features are structurally established. In order to engage in a person agreement relationship, two terms must establish a particularly close structural connection-simplifying somewhat, Baker's Structural Condition on Person Agreement (SCOPA) says that the head that has the person feature must have the phrase with the matching person feature in its specifier position or in an adjunction position to its projection. For person agreement to be possible, it is not sufficient for there to be an Agree relationship between the probe (the head) and the goal (the phrase). This in itself does not yet explain the fact that there is person agreement between subjects and finite verbs but not between subjects and adjectives. But Baker had already argued in previous work, on independent grounds, that adjectives do not project their subjects in the specifier of their own phrase: the subject of AP originates outside AP, higher up the tree (though see Sect. 2.3 of Omer Preminger's commentary for a possible alternative compatible with AP-internal base-generation). Establishing a SCOPA-compliant relation between a predicate adjective and its subject would have to involve either lowering of the subject into the AP (which is generally illegitimate in syntax) or raising of the adjective to the functional head that introduces its subject (which, on Baker's assumptions, would turn the adjective into a verb). Therefore, it is never possible for an adjective to show person agreement with its subject: wherever we find cases in which it seems as if this is possible, we are dealing with a deadjectival verb (as in This leaf yellows in autumn, on a par with clearly verbal This leaf reddens in autumn), not with a 'pure' adjective (I regard [this leaf as yellow(*s)]).

SCOPA also predicts that, while the literature has documented plenty of cases of agreement-at-a-distance involving number (as for instance in Tsez, Passamaquoddy, Innu-Aimûn, and Itelmen; see Polinsky and Potsdam 2001, Bruening 2001, Branigan and McKenzie 2002, and Bobaljik and Wurmbrand 2005), there can be no such agreement-at-a-distance for person. Baker presents a number of empirical case studies to show that this predication is accurate; but Preminger's commentary reveals data from Basque that suggest that there is no perfectly absolute ban on long-distance person agreement. Perhaps a particularly striking instance of SCOPA is object agreement 
in the Finno-Ugric language Northern Ostyak (though see the end of Preminger's Sect. 3.3 for the outlines of an alternative approach). What is so striking about the Northern Ostyak object agreement facts is that it would at first blush appear that the object is not particularly distant from the head with which it agrees: in a simple transitive clause, the object and the verb (which is the head on which object agreement is expressed) are typically right next to one another. But in Northern Ostyak, probably like in its more populous relative Hungarian but quite unlike in many other languages, the head controlling object agreement is actually $\mathrm{T}$, the tense-head of the clause: in Northern Ostyak, the exponent of object agreement shows up outside the tense morpheme, which would be entirely unexpected (from the perspective of Baker's 1985 seminal Mirror Principle) if the host of object agreement were a functional head lower in the structure than $\mathrm{T}$. With $\mathrm{T}$ being the controller of object agreement, and the object never actually raising into the specifier domain of the T-head, object agreement is at best a case of Agree, not one that would comply with SCOPA. It follows, therefore, that object agreement in Northern Ostyak cannot involve the person features: finite verbs agree with their subjects for person and number, but with their objects for number only. There is thus a difference between long-distance number agreement and long-distance object agreement. But as Preminger points out, the theory probably should stop short of giving a blanket licence to the former and imposing a blanket ban on the latter: the truth seems to lie somewhere in the middle, with long-distance agreement of both kinds being 'fragile' (though to relatively different degrees) while local agreement is much more foolproof.

Baker's contribution to this special issue, and Preminger's comments on it, highlight the structural constraints on agreement. For Nevins, too, structure is essential: in particular, he draws attention to the kinds of things that can and cannot happen in structural configurations in which two objects, or the subject and the object, are equidistant from the probe that is seeking to check its person or number feature under closest Agree. In such equidistance configurations, the probe can in principle engage in Multiple Agree relations_-and it is such Multiple Agree that is responsible for what Nevins calls 'omnivorous number' effects: cases in which a probe can pick as its goal for number-Agree any or even all of the arguments that are equidistant from it (as in the Soazza dialect of Italian, where la la tSam-an '3fem 3fem call-fem.pl' can mean any of the following: 'she calls them fem $_{\text {', 'they }}$ fem $_{\text {call her', and 'they }}$ fem call them $\mathrm{fem}_{\mathrm{f}}$ '). But even in equidistance contexts, there are restrictions on the kinds of Multiple Agree relationships that can be established. One of these restrictions is a simple reflex of the fact that the feature for which we might want to establish a Multiple Agree relationship is just not morphosyntactically present: Nevins makes this argument for number, showing that it is a privative feature in the morphosyntax, with only the [plural] value specifiable; hence 'omnivorous number' effects are strictly confined to plurals and unattested with singulars.

The other restriction on Multiple Agree in equidistance configurations manifests itself in the realm of person, in the famous Person Case Constraint effects first discussed at great length in Bonet (1991). Even when two elements (always clitics, for reasons discussed by Nevins) are equidistant from a probe with a specification for person, Multiple Agree cannot always transpire. What we find is that Multiple Agree is successful only in the presence of a continuous agreement path. A probe that is 
seeking to establish an Agree relationship for the marked feature [+participant] (for first or second person) will fail to so do if there is a third-person element on the agreement path because the [-participant] third-person element intervenes between the $[+$ participant $]$-specified probe and the [+participant $]$ goal. Though the probe has no trouble Agreeing with the [-participant] element in this kind of environment, it cannot Agree with the [+participant] goal. This delivers the PCC effect: They showed $\operatorname{him}_{\mathrm{IO}} m e_{\mathrm{DO}}$ is not expressible with two object clitics because the probe fails to Agree with the [+participant] direct object clitic across the [-participant] indirect object.

The PCC effect is thus an intervention effect-more specifically, an effect of the intervention of a bearer of the unmarked feature on the agreement path from a marked-feature probe down to the matching goal. The path-breaking effect of thirdperson elements is understandable in this way only if third person is morphosyntactically specified (at least on personal pronouns; see below), as [-participant]: it cannot be, in this way of thinking about PCC effects, that third person is universally 'non-person', complete lack of specification for person, as Benveniste (1966) had it. But singular is the complete lack of specification for number in the morphosyntax, Nevins argues. And as a result of that, we expect to get no 'Number Case Constraint' effects: no language should show a ban specifically on the expression of I showed her $_{\mathrm{IO}}$ them $_{\mathrm{DO}}$ with a singular indirect-object clitic and a plural direct-object clitic. Moreover, it is precisely because of the hypothesis that number is a privative feature in the morphosyntax that we get 'omnivorous number' effects of the type described in the previous paragraph-and conversely, we expect to find no such omnivory in the case of person.

In her commentary on Nevins' paper, Susana Bejar puts both of these predictions of Nevins' theory under the microscope. She argues that the fact there is no Number Case Constraint may not actually follow from this theory. She shows that combinations of dual and plural arguments, for which underspecification might not be a factor (it is only exploited by Nevins for the singular, though one could of course imagine the construction of a feature system in which dual and plural could be relatively underspecified vis-B-vis one another), should be able to deliver 'Number Case Constraint' effects - even though even in the case of such combinations, no such effects seem to be found in the data. So in the realm of number, Nevins' theory might underpredict. Conversely, in the domain of person, Bejar presents data that suggest at first sight that it overpredicts. The agreement facts of German specificational copular sentences, in particular, seem to indicate that 'person omnivory' may not be entirely non-existent. But here Bejar points out that such facts can actually be made compatible with Nevins' Multiple Agree theory if a more flexible stance is taken on the specification of third person, allowing for underspecification for person under particular circumstances (whose roots remain to be more profoundly understood: the possible link between intensionality and person underspecification that Bejar draws attention to is highly intriguing but also rather difficult to properly understand given our present state of knowledge). A less rigid approach to the specification of third person may thus ultimately allow Multiple Agree to get even the (apparent) cases of 'person omnivory' to fall into line. In any event, it certainly seems true that even if there is no black-and-white contrast, person omnivory is rather less widespread than number omnivory. 
Omnivory is just one strange trick played on the morphosyntax by the number feature. We see number rearing its wizard-like head in other contexts as well. Thus, Kimball and Aissen (1971) have drawn attention to the fact that in certain varieties of English (spoken mainly in the Eastern United States), when the head of a relative clause is plural but the subject of the relative clause is a non-pronominal singular, the finite verb can appear without the $-s$ that would normally be expected in the presence of a third-person singular subject: the people who Clark think(s) are in the garden. And the sentence-processing literature is replete with discussions of so-called 'agreement attraction' effects whereby finite verb agreement is 'attracted' to some element other than the subject noun phrase itself, as in The key to the cabinets $\{$ is/are $\}$ missing. It is significant that, just like omnivory, these peculiar effects are possible with number (and, in the case of attraction, with gender as well, although to a lesser extent than with number) but not with person: as Baker points out in his contribution, *I who Clark am hoping am in the garden (an attempt at creating a 'Kimball \& Aissen effect' for first person) is robustly impossible; and Nevins notes that there is no 'agreement attraction' for person (*The story about me am interesting).

There are pervasive differences in morphosyntactic behavior, therefore, between person and number-and to the extent that the kind of behaviour attested with number can be replicated for gender, it turns out that gender patterns with number rather than with person. Person, then, appears to be special among the phi-features. This is also apparent in the interesting ways in which morphological person marking can sometimes be misaligned with the referential properties that one would normally assume to be associated with the person marking in question. We see this in the context of polite

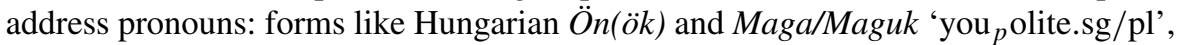
Spanish Usted(es), Dutch $U$, and German Sie are all formally third-person elements, the German one moreover being uniformly plural, regardless of whether the addressee is a single individual or a group (in that respect patterning like French vous, which, however, is formally a second-person form; more about vous's behaviour in Sect. 3, below). The Dutch case is particularly peculiar in the context of person. With all verbs whose second-person and third-person singular inflections are syncretic in subjectverb word order but discrete in verb-subject order (jij/hij gaat ' $\mathrm{you}_{\mathrm{sg}} /$ he goes'; but $\mathrm{ga}$ jij vs. gaat hij), $U$ behaves like a third-person subject ( $U$ gaat and gaat/*ga $U$ ). But with verbs that have a dedicated second-person singular form, $U$ shows mixed behaviour: in subject-verb order, $U$ then always allows second-person inflection on the finite verb ( $U$ bent 'you are.2sg', $U$ hebt 'you have.2sg'), and in the case of zijn 'be' clearly prefers that inflection in present-day Dutch ( $U$ is 'you is.3sg' is very archaic; on the other hand, $U$ heeft 'you has.3sg' is perfectly fine alongside $U$ hebt); but in verb-subject order, the $-t$ deletion rule that is normally operative with second-person forms never takes effect when the subject is $U-$ we get bent $U$, not *ben $U$, and hebt $U$ rather than *heb $U$ (except in informal rapid speech; but as an effect of speech rate and register, this is most likely a performance effect, not something regulated by the morphosyntax). Thus, the Dutch polite address form $U$ is a peculiarly idiosyncratic creature: it is generally a third-person form (as is apparent also from the fact that it can antecede the third-person anaphor zich), but it shows some vestigial second-person traits, without ever being fully aligned with the second-person singular pronoun jij.

It is natural to think that the vestigial second-person properties that the Dutch polite address pronoun evinces are a reflex of the fact that it is, after all, an address 
form: it is used with reference to the interlocutor, and the interlocutor is usually referred to with the aid of a form specified for the feature [+participant], which third-person forms do not have. But formally third-person forms can be recruited not just to make reference to the addressee: they can even be used to refer to the speaker, as in yours truly, your present interlocutor, or Daddy. Such 'imposters', as Collins and Postal (2011) have called these things, have a complex morphosyntactic signature-certainly too complex to summarise here. But what is particularly germane to the discussion here is the fact that forms like Daddy, when used with reference to the speaker, never show first-person behaviour in the domain of verb inflection (Daddy $\left\{\right.$ is $/ *^{*}$ am $\}$ going to be with you soon), and generally exhibit third-person behaviour in the context of anaphor binding - although here it turns out to matter whether the 'imposter' precedes or follows the anaphor in the linear string (cf. Daddy will shave $\{$ himself/*myself $\}$ and To keep $\{$ himself/? myself $\}$ from getting sunburned, Daddy will put on suntan lotion); see Collins et al. (2009) for a questionnaire study. Whatever underlies the difference between anaphoric and cataphoric dependencies, it seems clear that being used with reference to the speaker does not give 'imposters' a blanket licence to take on formal first-person properties. Though the Dutch polite address facts might suggest a limited amount of notional agreement behaviour, there are severe limits on such behaviour. This is the perfect cue for a discussion of the difference between formal/grammatical and notional agreement.

\section{Grammatical versus notional agreement}

For the German polite address form Sie, I have already pointed out that it is doubly remarkable: not only is it a third-person form used to address the interlocutor, it is also uniformly plural regardless of the number of people it is used to address. We see this latter property (though not the former) also in the French polite address form vous, whose behaviour is a central topic of Stephen Wechsler's contribution to this special issue.

A well-known puzzle about French vous is that it can co-occur, at the same time, with a finite verb bearing plural number inflection and a predicate adjective showing singular concord-there is an alternation between Vous êtes loyaux 'you are.2pl loyal.pl' and Vous êtes loyal 'you are.2pl loyal.sg'. The latter, used when the speaker is addressing a single person, is grammatically quite puzzling: how can a single form vous simultaneously control plural inflection on the finite verb and singular inflection on the predicate adjective? An important descriptive generalisation appears to be that formally plural polite address pronouns can only show the kind of alternation we saw in French (between plural loyaux and singular loyal) when the agreement target shows no person inflection. Here we are finding our way right back to something that is at the heart of Baker's contribution. Predicate adjectives and finite verbs both show number inflection controlled by their subjects, but only the latter show person inflection as well; and it seems that it is thanks to the absence of person inflection on adjectives that oscillation for number inflection in these polite address cases is made possible: when the agreement target agrees with the polite address form for person, 
it must also grammatically agree with it for number. Wechsler establishes this generalisation on the basis of a sizable sample of languages (with Persian being the only apparently exceptional case, but there are mitigating circumstances there).

The key to understanding this generalisation, according to Wechsler, is a combination of two things: (a) a particular outlook on the person feature, and (b) a perspective on the division of labour between notional or semantic agreement and grammatical or morphosyntactic agreement. For $(a)$, Wechsler makes a distinction between 'Concord' and 'Index agreement': phi-features are grouped into two different kinds of feature bundles, 'Concord' and 'Index' features, with the latter tied to the referential index of the bearer of the phi-features. The person feature is special in that while number and gender features can be contained in both Concord and Index feature bundles, the person feature can only be included in the Index bundle. Regarding (b), Wechsler and Hahm (2011) argue that notional/semantic agreement results from the controller lacking the relevant phi-feature to trigger grammatical agreement-a conclusion which they derive from their Agreement Marking Principle, laid out in detail in Wechsler's contribution. In turn, the Agreement Marking Principle finds its roots in commonsense reasoning, as Wechsler explains in his paper.

How does this help us account for the French vous-facts mentioned two paragraphs back? The referential Index of vous inherently has the features [second person] and [plural]; these are the Index features of vous. But vous happens not to have any Concord phi-features. This has immediate consequences for the ways in which vous can agree with finite verbs and predicate adjectives. Finite verbs show Index agreement, allowing them to agree with their subject for the feature person (which, recall, does not occur in the Concord feature bundle). Since the French polite address pronoun vous has a bundle of Index features, the finite verb has no trouble Index-agreeing with vous, and will automatically agree with vous for the grammatical number feature included in the pronoun's Index feature bundle (i.e., [plural]). Adjectives, by contrast, show Concord-and the French polite address pronoun vous by hypothesis does not have any Concord features. This means that vous cannot establish a Concord relationship with the predicate adjective. And as a result of this, the adjective defaults to the semantics: when the controller (here vous) lacks the relevant phi-features, the target determines its inflectional form on the basis of the semantic properties of the controller. So in a context in which vous is used to refer to a single person, the adjective will show singular Concord, despite the fact that vous's Index feature bundle includes [plural].

Wechsler provides some interesting speculations in closing regarding the roots of the difference between finite verbs and adjectives regarding their agreement behaviour. He suggests that phi-feature inflection on finite verbs historically derives from pronoun incorporation, whereas phi-feature inflection on adjectives comes from incorporated classifiers. Whereas pronouns are stratified for Index features, classifiers derive historically from common nouns, which are trivially third person. Here Wechsler follows Benveniste (1966) in assuming that person is not specified on common nouns. This stance is not necessarily irreconcilable with Nevins's argument that third person is [-participant], not the lack of a specification for person: Nevins is concerned with the person and number properties of clitics, which are pronominal; 
saying that third-person pronouns are specified for person need not entail making the same claim for common nouns. If common nouns are not person-specified, and if phifeature inflection on adjectives descended from incorporation of nominal classifiers (themselves descended from common nouns), the fact that predicative adjectives cannot show Index agreement then follows from Wechsler's approach. And it is this lack of Index agreement for adjectives that Wechsler exploits to account for the fact that notional/semantic agreement is resorted to in the choice of inflection for predicate adjectives with polite address pronouns like French vous.

The role of notional agreement is also prominent in Kay Bock and Erica Middleton's joint contribution to this special issue, and also in Julie Franck's commentary. Reviewing the body of psycholinguistic literature on agreement in sentence processing, Bock \& Middleton draw a subtle picture of the division of labour between purely formal number marking and notional number marking. One of the central findings of experimental work is that there is a cline of notional number effects: such effects are highly prominent in garden-variety pronominal coreference relationships, less prominent but consistently present in the agreement relationship between a subject and its finite verb, and not at all prominent in so-called 'agreement attraction' contexts (instantiated by relationships between a subpart of the subject, on the one hand, and the finite verb or a coreferent pronoun, on the other: [The key to the cabinets] are missing and [The key to the cabinets] disappeared, didn't they?, resp.). In the realm of attraction, finite verbs and pronouns are basically equally sensitive to the grammatical vs. notional number distinction. Grammatical number is a powerful force in attraction, for finite verbs and pronominal coreference relationships alike; and quite the contrary is true for notional number, again for both cases. Thus, although a formally singular noun like team might very well trigger plural agreement on the finite verb when it itself heads the subject (esp. in British English: The team are still deliberating) or antecede a plural pronominal (The team will soon find out whether they won the competition), such a noun will not bring about plural verb inflection or license a coreferent plural pronoun in a question tag when it is not itself the head of the subject. Quite in general, a formally singular noun embedded inside the subject cannot trigger attraction-regardless of whether it is notionally singular or plural. When it comes to attraction, therefore, there is a major split in the number system between grammatical singulars and grammatical plurals: the latter lead to attraction quite frequently whereas the former do so vanishingly rarely.

This finding is perfectly in line with a treatment of the number system (of pluralitive languages that make a two-way distinction between singulars and plurals) in terms of a privative opposition between [plural] and unmarked. Only formal plurals have the morphological wherewithal to assert themselves on a syntactic level higher than the one at which they find themselves spelled out: the feature [plural] can, if you will, 'percolate' up to a subject noun phrase that is itself not marked for number, and end up controlling phi-feature based agreement relationships regulated at the clausal level; since singulars lack a specification for number, they can never rear their heads beyond their immediate structural vicinity. 


\section{Agreement attraction}

The ability on the part of subject-embedded plurals to assert their plurality outside their containers is the prerogative of plural common nouns: plural pronouns very strongly tend not to trigger attraction (see den Dikken 2001 for details). This suggests that attraction effects are a matter of sentence grammar, the competence system, and not merely a matter of performance: it is in the morphosyntax that common nouns and pronouns can be formally distinguished; and it is in the morphosyntax that number presents itself privatively, with the plural as the marked member of the opposition. The fact that notional number does not seem to play a role in controlling attraction enhances this conclusion. So do Kayne's (1998) findings (also discussed in den Dikken 2001) on the role played by the quantificational properties and the scope of the attraction trigger.

The structure-based nature of attraction phenomena is stressed particularly by Julie Franck in her commentary, and in her previous (joint) work-esp. Franck et al. (2006). In this latter paper, the role of intermediate traces of moved constituents and the difference between Agree-based agreement and Spec-Head agreement in the realm of attraction phenomena are discussed in detail. The special strength of SpecHead relations, which appear to be particularly immune to interference from attraction, reminds us of Baker's SCOPA. The findings of these studies combined suggest that Agree should not render Spec-Head agreement obsolete.

More about the role of the morphosyntax in attraction phenomena could be gleaned from an investigation of the behaviour of different types of number-marking systems in the context of attraction. So far, all work on attraction phenomena has concentrated on pluralitive languages that make a two-way singular/plural distinction; languages with duals and trials, and singulative languages (which have morphologically unmarked plurals and marked singulars) have not been investigated in this connection to date. In languages making more than a two-way number contrast, number is not a privative opposition (something that Bejar also draws attention to in her commentary on Nevins' paper, as we saw in Sect. 2, above): more than just the feature [plural] will be morphosyntactically specified and active. For singulative languages, it makes intuitive sense to take [singular] to be the marked feature. If this is correct, and if it should turn out that in singulative languages agreement attraction effects occur and single out singulars as attraction triggers, this would suggest that agreement attraction is robustly controlled by the morphosyntax. Unfortunately, singulative languages as well as languages with multiple distinctions in the number system (singular, dual, trial, plural) tend, in general, to be less well-researched than pluralitive languages with a privative number system; since native speakers of such languages are not readily signed up for psycholinguistic experiments, we probably should not hold our breath for results on attraction experiments run on singulative languages or languages with duals and trials.

But thankfully, we can do something similar without having to recruit speakers of endangered languages, by looking at gender attraction. As in the case of number, gender systems come in a variety of different flavours: in some, there is a two-way contrast (say, between neuter and common gender, as in Dutch; or between feminine and masculine, as in Romance); in others, more gender contrasts are made (as in 
German or Greek, for instance). For two-way gender systems, a privative approach is possible in principle - though morphological investigations should determine, for each individual case, whether it is adequate. For systems making three or more gender distinctions, it will not be. But markedness considerations may play an important role here, too: thus, for the German definite article system, feminine gender is arguably the unmarked option, and masculine the most marked one (see Blevins 1995 for a careful analysis of the German article system from the point of view of feature geometry).

More specifically, if we follow the approach to the division of labour between syntax, morphology and phonology represented by the theory of Distributed Morphology (Halle and Marantz 1993 and subsequent work), it is the Vocabulary Items (German die 'the.fem', der 'the.masc' and das 'the.neut') that show these markedness relationships. The terminal morphemes of the syntactic phrase markers of German may very well be specified fully, each D having an explicit mark for gender. These terminal Dmorphemes are eventually paired up with phonological matrices that optimally match their feature content in accordance the Subset Principle, which gives pride of place (among the candidates that are specified only for features carried by the terminal morpheme) to the Vocabulary Item that matches the greatest number of features under the terminal morpheme. If it should turn out to be confirmed, for a particular language, that the terminal D-morphemes in the morphosyntax are all fully specified for gender and that it is only the Vocabulary Items spelling out these terminal morphemes that are variably (under)specified for gender, then it will become very interesting to investigate the distribution of gender attraction effects in that language. For if it turned out that, in this language, all genders are equally active on the gender-attraction front, that suggests that gender attraction plays itself out in the morphosyntax; but if, in a language whose terminal D-morphemes are all fully specified for gender, only the marked gender(s) (i.e., the gender(s) that are specified on the Vocabulary Items that spell out the terminal D-morphemes) can trigger gender attraction, then attraction must be a post-syntactic affair.

In the previous paragraph, I used gender in the German article system for expository purposes. But German is not particularly helpful for studying gender attraction: it does not mark gender on predicate adjectives, for instance. Romance is more useful in this respect; but these languages merely have a two-way gender distinction, so they are not the optimal guinea pigs for the gender-attraction laboratory either. There is some work on gender attraction effects in the literature: both Bock \& Middleton's paper and Julie Franck's commentary make mention of this. But more extensive investigation of gender attraction that takes into account the difference between gender specification on the terminals of syntactic phrase markers and gender specification on the Vocabulary Items that spell out these terminal morphemes is called for.

Another potentially fertile research line could build on the fact that both number and gender have purely formal and notional manifestations. For pluralia tantum like trousers, pants, and jeans, number marking is not particularly meaningful (as is perhaps apparent from the fact that in the fashion industry it is now customary to use $a$ trouser, a pant and a jean to refer to the items of clothing in their entirety). Similarly, for a noun like Spanish mesa 'table', the fact that it is formally feminine means very little to the denotation of the noun. But alongside grammatical gender, there is also natural gender. Whether grammatical and natural gender behave differently in the 
realm of agreement attraction phenomena is a topic that would be worth exploring further in connection with the question of what the role of the formal grammar is in this context.

Attraction effects are standardly viewed as production errors, not as well-formed products of the grammar. Probing into the extent to which the morphosyntax regulates the distribution of attraction is something that the literature has actively engaged in to a certain degree already, as Bock \& Middleton's and Franck's contributions make clear. But it would be good to see research efforts in this direction intensified in the future. The results of further experiments addressing the kinds of questions raised in the previous paragraphs are eagerly awaited.

\section{Agreement?}

Both Wechsler and Bock \& Middleton find roles to play for notional or semantic agreement in certain pockets of the grammar. But Wallis Reid, in his contribution to this special issue, calls the very existence of 'notional agreement' into question: "proposing that a verb can "agree with an idea" (rather than express an idea) simply makes no sense', he says. Not only does he reject notional agreement, he dispenses with all agreement, presenting a very different perspective on the phi-featural link between a subject and a finite verb (in English).

Up to this point in this introduction, most of the time when I talked about cases of systematic covariation of phi-feature marking on two terms in a syntactic structure, I couched the discussion in terms of the notion agreement. This is the predominant way in which the linguistics community has approached such relationships of systematic covariation. But it is not the only logically possible one. It is perfectly imaginable, a priori, that the two terms have their phi-features chosen independently of one another, and that there is only a statistical tendency (rooted in something outside formal grammar) for the two to have the same phi-features. This is the approach Reid (1991) takes in his study of verb and subject number in English, couched in the functionalist approach represented by the Columbia school, centered around the works of William Diver-an approach anchored firmly in the Saussurean anti-nomenclaturist tradition (see Otheguy 2002 for a useful overview), in which linguistic data are analysed as much as possible without reliance on antecedently assumed formal or structural notions such as 'subject', 'verb' or 'agreement', and in which the notion 'subject-verb agreement' is hence an imponderable. Reid reports on and updates his earlier work in his contribution to this phi-feature special. Reid's paper and Ellen Contini-Morava's commentary on it are deliberately placed at the end of the set because both of these contributions give the reader occasion to review retrospectively some of the notions taken for granted in the papers that precede them.

Reid champions a sign-based approach to English number morphology in which the choice of phi-feature inflection on the finite verb is not a reflex of a formal relationship of agreement between the verb and its subject but instead a decision, made independently for the subject and the verb, that is based on the semantic contribution of number marking to the message the speaker means to convey. His work contains detailed investigations of a large variety of corpus examples of 'unusual' number 
inflection on the verb, for which explanations are provided within the discourse contexts that the utterances are a part of. Each time, the choice of verb number and the choice of subject number are shown to be reflexes of the demands imposed by the need for textual cohesion. Reid argues that textual cohesion sometimes prefers the selection of plural verb number in the presence of a singular subject. Authors can be found to oscillate between singular and plural verb number in combination with the same plural subject, sometimes within the space of just a few sentences. And Reid's (con)textual analyses shed a revealing light on what moved these authors to choose singular verb number on one occasion and plural verb number on the other.

But for Reid, equally important as cases of 'non-agreement' between subject and finite verb are cases in which verb number and subject number have the same valuecases of what the formalist literature calls agreement are subjected to exactly the same amount of (con)textual scrutiny as cases in which the verb and the subject are marked differently for number. In the sign-based approach to verb and subject number, every assignment of a particular number inflection to a verb and its subject is a deliberate communicative decision. Lack of number-feature matching is no more special, in itself, than agreement: nothing in Reid's theory would lead one to expect phi-feature matching to be the normal case, and non-matching some aberration.

It does remain remarkable, however, that there is a considerable imbalance between, on the one hand, cases in which the subject is plural and the finite verb is singular, which can be found with relative ease in English (and in some varieties are even the norm: the 'Northern Subject Rule' routinely delivers things like The boys is coming), and, on the other, situations in which a singular subject shows up together with a plural finite verb, which are quite rare. Collectives like committee or team, and cases of agreement attraction (The key to the cabinets are missing) aside, singular subjects strongly tend to combine with a singular finite verb. At the end of his paper, Reid proffers Yes, Virginia, there are a Santa Claus as an interesting specimen of a singular subject combining with a plural verb, and tells us what must have moved the author to use plural are here. But it may be significant that this is an existential there-sentence. As is well known, such sentences present 'agreement puzzles' in the other direction as well: There is/was/seems to be many people in the room (see Schütze 1999; Sobin 1997; den Dikken 2001, i.a., for discussion). The there-less sentence Many people is in the room is probably very hard to contextualise (it is clearly different, because of the nature of the predicate, from Pancakes is nice, referred to by Wechsler in his paper), and will strike speakers of English not following the Northern Subject Rule as deviant. In light of this, the status of A Santa Claus exist, with a bare (i.e., -s-less) verb, should be examined in tandem with There are/exist a Santa Claus to see whether the there-less sentence could serve its particular communicative purpose in the relevant context as efficaciously as the sentence with there. There is, to be sure, an information-structural effect associated with the use of there-existentials. So it is conceivable that a difference between There are/exist a Santa Claus and A Santa Claus exist could be related to the pragmatic properties of the constructions involved. The playing field is never going to be level here: the two sentences differ both in terms of a purely grammatical property (post- vs. preverbal placement of the notional subject) and in information-structural terms, and it will always be difficult to be sure which of these differences is the culprit. As Contini-Morava puts it at the 
end of her commentary, '[t]aking meaning seriously ... captures the very essence of language' - but it seems unlikely that it will capture everything we need to understand about the behaviour of phi-features.

Many examples in Reid's work are copular sentences in which the copula has the same number specification as the noun phrase to its right. Some of these (but by no means all: see Reid's (16)-(18), for instance) are specificational copular sentences (in the sense of Higgins 1979)—Reid's very first example, The biggest threat to the joint force are the hundreds of IEDs Taliban fighters have planted in and around Marja, is an immediate case in point. Specificational copular sentences in English are often said to demand agreement between the copula and the precopular noun phrase (see Heycock 1994; Moro 1997). But Declerck (1988:79-80) points out that this is by no means categorical: 'in specificational sentences the number of the copula can apparently be determined by that of either the superficial subject NP or the variable NP'. The formal syntax literature has never fully come to grips with the circumstances under which the postcopular noun phrase of specificational copular sentences controls the number marking on the finite copula and under which it does not. Closely related languages also differ rather markedly on this point. In Dutch specificational copular sentences with a singular predicate nominal and a plural subject, the plural subject always seems to determine the number inflection of the finite copula, irrespective of whether it precedes or follows the copula. But it is even possible for plural inflection to arise in Dutch copular sentences in which neither of the two nominal terms has a [plural] specification: Wat zijn dat? 'what are that, i.e., what are those?' is a noteworthy case of what one might call numerus ex machina, or 'number out of the blue'. Such cases, for which it would seem patently obvious that the number inflection of the finite copula is not a case of agreement, would appear to be grist to Reid's millthough the fact that, outside of this particular copular context, neither wat nor dat can otherwise combine, as subjects, with a plural verb form will obviously remain to be understood.

Reid confines himself entirely to English number-and as Contini-Morava stresses in her commentary, Reid's analysis does not intend to make predictions about number in other languages, or about the behaviour of different phi-features. But in light of the fact that some of the other contributions to this special issue have found number and person features to behave markedly differently in a variety of respects, and because person is another phi-feature that is expressible both on the subject and the verb in English, it would be interesting to reflect on the vicissitudes of a sign-based approach to (English) person. Person-marking mismatches between subject and verb seem to be entirely absent: I already noted that 'imposters' (which are formally third person but notionally first person) can only combine with a third-person verb form, that (as Baker notes) 'Kimball \& Aissen effects' do not manifest themselves for person, and that (as Nevins points out) 'person attraction' does not seem to occur. If indeed this is systematic, one would like to know what it entails for a theory in which subject and verb are assigned their phi-features autonomously. Reid amply demonstrates that for the phi-feature number, such autonomy is warranted; if it turns out not to be manifest in the case of person, it will be important to ask why person marking cannot have the same kinds of communicative functions that number marking apparently can have. 


\section{Whether we agree or not ...}

In the preceding pages, we have come across a variety of contexts in which not all the phi-features behave alike. While number and gender seem to a very large extent to exhibit very similar behaviour (there are 'attraction effects' for both, there is a grammatical vs. notional distinction for both), person is different: person shows no 'weird' agreement effects, and there is little credible evidence for 'notional person' (in the case of 'imposters', the fact that one can have cataphoric dependencies between a first-person anaphor and a third-person imposter, as in ? To keep myself from getting sunburned, Daddy is putting on suntan lotion, is probably more a fact about control of the implicit subject of the infinitival adjunct clause than about the imposter itself). At a more microscopic level, person is also different from number in showing Person Case Constraint effects, which find no replica in the realm of number; and conversely, number differs from person in giving rise to omnivory effects.

The individual contributions to this special issue provide perspectives on these various differences between person, on the one hand, and the other phi-features (number, in particular), on the other. Baker's SCOPA imposes stringent structural restrictions on the checking of person features. Nevins argues that Multiple Agree renders omnivorous number effects possible while simultaneously explaining Person Case Constraint effects, as a result of the combination of a structural condition (equidistance) and the featural properties of person (a binary feature: [-participant] vs. [+participant], with a further subclassification for [+participant] to differentiate between first and second person) and number (which involves a privative opposition between [plural] and lack of specification for number). And Wechsler and also Bock $\&$ Middleton capitalise on the role of notional versus grammatical agreement, with Wechsler in particular providing an account for the fact that polite address pronouns that are formally plural can agree notionally with predicate adjectives, which themselves cannot agree for person, but not with finite verbs, which person-inflect and therefore automatically also show grammatical rather than notional agreement with their subjects.

Do these various perspectives on person versus number add up to a single unified account? They may. If indeed the Index agreement we find on finite verbs derives historically from pronoun incorporation (as Wechsler suggests), and if the subject of adjectives originates in a structural position from which incorporation into the phi-feature checking functional head is impossible (in line with what Baker has proposed), then the absence of person agreement with predicate adjectives will immediately fall into place. And if (weak) pronouns are different from common noun phrases in needing to establish a very close structural relationship with the functional head with which they agree, SCOPA may reduce entirely to properties of pronouns. A link with Rouveret's (1991) account of subject agreement in VSO clauses in Welsh suggests itself particularly prominently in this connection. There is a difference in Welsh between full-nominal and pronominal subjects (whether overt or null) when it comes to the agreement form they trigger on the finite verb: full-nominal subjects do not show number agreement with the finite verb (i.e., the Welsh equivalents of the child and the children both co-occur with a singular verb form), but pronominal subjects must so do. Rouveret argues that this is a consequence of movement of the 
functional head Num of pronominal subjects up to a position adjoined to the functional head in the structure of the clause where the verb's phi-features are checked (let us call it I(nfl), to give the node its conventional name). Such movement creates a SCOPA-compliant structural configuration in which person agreement is possible; and with the full-nominal subject staying in the complement of I in Welsh VSO clauses, person agreement between the finite verb and a full-nominal subject is impossible. Movement of the Num-head of pronominal subjects up to I, B la Rouveret (1991), is effectively a case of pronoun incorporation of the type that Wechsler suggests is the historical source for Index agreement with finite verbs. In Welsh, we may see this in action in the synchronic syntax.

In Rouveret's proposal, it is important that number be represented on a head (labelled Num, following Ritter 1991) that is different from D as well as N: nonpronominal noun phrases are DPs that include Num but prevent Num from raising (due to locality: D structurally intervenes between I and Num, and Num cannot manoeuvre itself around D); and overt pronouns themselves are not being displaced as a result of movement up to $\mathrm{I}$, so it cannot be that $\mathrm{N}$ (which is where pronouns are spelled out in Welsh) is itself doing the moving. This line of thinking thus renders plausible on morphosyntactic grounds the postulation of a functional head for number, with its own X-bar projection, NumP. For gender, Picallo (1991) has suggested that it projects autonomously in the syntax as well. Since the contributions to this special issue have little to say about gender, it is difficult to take a stand here on the GenP hypothesis. But one is led to wonder whether person should be 'emancipated' in the same kind of way. In Welsh, raising of Num to I brings about not just number agreement between the finite verb and the pronominal subject, but person agreement as well. This could logically be a consequence of the fact that the Person head is necessarily pied-piped by movement of Num to I; but such an approach is not necessary: one could equally well derive this by encoding the person features directly on the Num head. The question of whether a PersP should be recognised in the syntax is not answered by these data, therefore. A PersP is not needed in order to account for the Welsh facts, or Wechsler's Index agreement vs. Concord distinction. But Preminger suggests that recognising a separate PersP (which he calls ' $\pi \mathrm{P}$ '), alongside a NumP (or '\#P'), placed on the clausal spine (hence not in the extended projection of the noun but in the extended projection of the verb), would be beneficial for capturing the effects of a weakened version of Baker's SCOPA: in particular, he argues that with the functional head checking person merged lower than the functional head for number, the theory can make sense of the implicational relation between disruptions of agreement involving number and disruptions involving person, and of the fact that agreement failures manifest themselves only at a distance and never in local configurations.

Where does all this leave us when it comes to the label 'phi-features'? To what extent does it actually make sense to talk in a generalising way about 'phi-features', subsuming person, number, and gender features? In light of the differences in morphosyntactic behaviour between person, on the one hand, and number and probably also gender, on the other, it seems illusory to group all three traditional phi-features into one overarching natural class. And beyond person, number, and gender, there has never been much agreement in the literature regarding other features that may or 
may not be classified under the rubric of 'phi'. Is animacy a phi-feature? What about definiteness? Or specificity? All of these properties have something to say about the referential properties of noun phrases: for the reference of a nominal constituent, it makes a difference what its person, number, gender, animacy, definiteness, and specificity properties are. If 'phi' is a shorthand for reference-related properties, then perhaps all of the above should be categorised under this rubric. But the proof of the pudding is in the eating: does it help us in any way to cluster these properties together under one roof, or does the roof prevent us from seeing the outside world in clear daylight? I do not profess to have the answer to this important question. But sometimes raising an important question is half the work.

Not surprisingly, there is no agreement on agreement among the various contributions to this special issue. There are, however, strong connections between these five papers and the commentaries on them which to a significant extent lend themselves to a unifying plot line that can be distilled from the special issue as a whole, as I hope to have demonstrated in this introduction. The five contributions, in conjunction with the four commentaries, show plenty of cross-fertilisation. And together they present a wide-ranging outlook on the problems posed by phi-feature inflection and agreement phenomena and their solutions.

Acknowledgements This special issue of $N L L T$ is the finished product of a symposium on phi-feature inflection organized by the guest editors of this issue at the LSA Annual Meeting in Chicago in 2008. This symposium was organized by the guest editor together with Judy Bernstein, Christina Tortora, and Raffaella Zanuttini. This quadrumvirate were, at the time, the co-PIs in a Collaborative Research project entitled 'The Comparative Morpho-Syntax of Appalachian English', funded by the National Science Foundation (BCS-0617210 (Bernstein), BCS-0616573 (Den Dikken), BCS-0617197 (Tortora) and BCS-0617133 (Zanuttini)). The LSA symposium was made possible in part by the NSF's financial support for this Collaborative Research project, which is gratefully acknowledged. Four of the five papers included in this special issue were presented at the LSA symposium; Stephen Wechsler's paper and all the commentaries were added later. Although a commentary was solicited for Wechsler's paper as well, it unfortunately did not materialise in time for inclusion in this special issue. I would like to thank all the contributors for their cooperation, and the reviewers of the papers for their careful and thoughtful work, and would like to include a special word of thanks to Judy, Christina and Raffaella for their outstanding collaboration throughout the Appalachian English project and, more particularly, in the realisation of the phi-feature symposium and, ultimately, of this special issue. Though this special issue eventually turned into a single-editor endeavour, I could never have managed it without their work on the project at the earlier stages and their continued support throughout the process of bringing this phi-feature special to publication. My heartfelt thanks to all. And of course I alone deserve the blame for this introduction or for the special issue as a whole.

\section{References}

Baker, Mark. 1985. The Mirror Principle and morphosyntactic explanation. Linguistic Inquiry 16: 373415.

Benveniste, Émile. 1966. Problèmes de linguistique générale. Paris: Gallimard.

Blevins, James. 1995. Syncretism and paradigmatic opposition. Linguistics and Philosophy 18: 113-152.

Bobaljik, Jonathan, and Susi Wurmbrand. 2005. The domain of agreement. Natural Language \& Linguistic Theory 23: 809-865.

Bonet, EulBlia. 1991. Morphology after syntax: Pronominal clitics in Romance. PhD dissertation, MIT.

Branigan, Phil, and Marguerite McKenzie. 2002. Altruism, A-bar movement and object agreement in InnuAimûn. Linguistic Inquiry 33: 385-407.

Bruening, Benjamin. 2001. Syntax at the edge: Cross-clausal phenomena and the syntax of Passamaquoddy. PhD dissertation, MIT. 
Collins, Chris, Guitard, Stephanie, and Jim, Wood. 2009. Imposters: An on-line survey of grammaticality judgments. NYU Working Papers in Linguistics, Vol. 2: Papers in syntax. New York: New York University

Collins, Chris, and Paul Postal. 2011. Imposters. Cambridge: MIT Press (to appear).

Declerck, Renaat. 1988. Studies on copular sentences, clefts and pseudo-clefts. Leuven/Dordrecht: Leuven University Press/Foris.

den Dikken, Marcel. 2001. Pluringulars', pronouns and quirky agreement. The Linguistic Review 18: 1941.

Franck, Julie, Glenda Lassi, Ulrich Frauenfelder, and Luigi Rizzi. 2006. Agreement and movement: A syntactic analysis of attraction. Cognition 101: 173-216.

Halle, Morris, and Alec Marantz. 1993. Distributed morphology and the pieces of inflection. In The view from building, Vol. 20, eds. Kenneth Hale and Samuel Jay Keyser, 111-176. Cambridge: MIT Press.

Heycock, Caroline. 1994. Layers of predication: The non-lexical syntax of clauses. New York: Garland.

Higgins, F. Roger. 1979. The pseudocleft construction in English. New York: Garland.

Kayne, Richard. 1998. Parameters and universals, 187-205. Notes on English agreement. CIEFL Bulletin 1. 40-67; reprinted in Richard Kayne, 2002. Oxford: Oxford University Press.

Kimball, John, and Judith Aissen. 1971. I think, you think, he think. Linguistic Inquiry 2: 242-246.

Moro, Andrea. 1997. The raising of predicates: Predicative noun phrases and the theory of clause structure. Cambridge: Cambridge University Press.

Otheguy, Ricardo. 2002. Saussurean anti-nomenclaturism in grammatical analysis: A comparative theoretical perspective. In Signal, meaning, and message: Perspectives on sign-based linguistics, eds. Wallis Reid, Ricardo Otheguy, and Nancy Stern, 373-403. Amsterdam: John Benjamins.

Picallo, M. Carme. 1991. Nominals and nominalizations in Catalan. Probus 3: 279-316.

Polinsky, Maria, and Eric Potsdam. 2001. Long-distance agreement and topic in Tsez. Natural Language \& Linguistic Theory 19: 583-646.

Reid, Wallis. 1991. Verb and noun number in English: A functional explanation. London: Longman.

Ritter, Elizabeth. 1991. Two functional categories in noun phrases: Evidence from Modern Hebrew. In Perspectives on phrase structure: Heads and licensing, ed. Susan Rothstein, Vol. 25 of Syntax and Semantics, 37-62. San Diego: Academic Press.

Rouveret, Alain. 1991. Functional categories and agreement. The Linguistic Review 8: 353-387.

Schütze, Carson. 1999. English expletive constructions are not infected. Linguistic Inquiry 30: 467-484.

Sobin, Nicholas. 1997. Agreement, default rules, and grammatical viruses. Linguistic Inquiry 28: 318343.

Wechsler, Stephen, and Hyun-Jong Hahm. 2011. Number markedness and polite plurals. In: Morphology, eds. Jonathan Bobaljik, Andrew Nevins, Hazel Pearson, and Sauerland Uli (to appear). 